\title{
Lower education among low-income Brazilian adolescent females is associated with planned pregnancies
}

This article was published in the following Dove Press journal:

International Journal of Women's Health

21 January 2017

Number of times this article has been viewed

\author{
Alexandre Faisal-Cury' \\ Karen $\mathrm{MTabb}^{2}$ \\ Guilherme Niciunovas ${ }^{3}$ \\ Carrie Cunningham ${ }^{4}$ \\ Paulo R Menezes' \\ Hsiang Huang ${ }^{4,5}$ \\ 'Department of Preventive Medicine, \\ Faculty of Medicine, University of \\ São Paulo, São Paulo, Brazil; ${ }^{2}$ School \\ of Social Work, University of Illinois \\ at Urbana-Champaign, Urbana, IL, \\ USA; ${ }^{3}$ School of Medicine, Federal \\ University of São Paulo, São Paulo, \\ Brazil; ${ }^{4}$ Department of Psychiatry, \\ Cambridge Health Alliance, Harvard \\ Medical School, Cambridge, MA, \\ USA; ${ }^{5}$ Department of Psychiatry, \\ Laboratory of Psychopathology and \\ Psychiatric Therapeutics (LIM-23), \\ Faculty of Medicine, University of \\ São Paulo, São Paulo, Brazil
}

\begin{abstract}
Adolescent pregnancy has social, economic, and educational consequences and is also linked to adverse perinatal outcomes. However, studies show a positive relationship between pregnancy and increased social status among low-income adolescents. This study aims to assess the association between planned pregnancy and years of schooling among low-income Brazilian adolescents. This is a secondary analysis of a cohort study conducted from May 2005 to March 2007 in public primary care clinics in São Paulo, Brazil. Participants $(n=168)$ completed a detailed structured questionnaire. Logistic regression was used to examine the association between years of schooling and planned pregnancy. After adjusting for the covariates income, wealth score, crowding, age, marital status, and race, planned pregnancy was independently associated with lower years of education (odds ratio: 1.82; 95\% confidence interval: 1.02-3.23). Although this finding may be related to these adolescents having less access to information and health services, another possible explanation is that they have a greater desire to have children during adolescence.
\end{abstract}

Keywords: adolescent pregnancy, planned pregnancy, Brazil, low-income population, women

\section{Introduction}

Adolescent pregnancy impacts not only the health and well-being of adolescents and their infants but also their life course trajectory with respect to social, economic, and educational outcomes. Teen pregnancy, in general, is less complicated from an obstetrical standpoint, with lower rates of cesarean section and other maternal complications. ${ }^{1,2}$ However, adolescent pregnancy is associated with poor perinatal outcomes, with worse health outcomes for infants including low birth weight and preterm birth. ${ }^{3}$ In addition, there may be other social consequences for the adolescent mother including later socioeconomic difficulties. These socioeconomic disadvantages include potential dependence on social welfare and unemployment. ${ }^{4}$ An association has also been found between unintended pregnancy and attainment of fewer years of schooling. ${ }^{5}$ Kane et al evaluated the effects of teen motherhood on schooling (using The National Longitudinal Study of Adolescent Health data set) and demonstrated educational consequences of teen childbearing, with estimated effects between 0.7 and 1.9 fewer years of schooling among teen mothers. ${ }^{6}$ Among a female population in Southern Brazil, unintended pregnancy was found to be associated with younger age ( $<20$ years), being described as black or mixed race, being single, smoking, multiparity, low family income, and household crowding. ${ }^{?}$

Despite these disadvantages, however, studies have shown a positive association between pregnancy and social status among poor adolescents in Brazil. As identified 
in the GRAVAD Survey, motherhood itself is viewed as a sign of enhanced social status among lower socioeconomic populations. ${ }^{8}$ Pregnant adolescents may receive increased attention and care from their relatives and friends because they are expecting a baby. Moreover, in the lower socioeconomic strata, motherhood also means early entry into adulthood, which adolescents and their relatives may welcome. The relationship between education and other socioeconomic indicators and early pregnancy is controversial. On the one hand, it is accepted that early reproduction acts as a springboard into poverty. On the other hand, lower education and poverty are considered causes but not consequences of early reproduction. Finally, the option of parenting in adolescence can also be understood as a life project for poor adolescents. For some adolescents with difficulties in achieving educational attainment, motherhood may be seen as an alternative. The aim of this study was to evaluate whether there is an association between planned pregnancy among adolescents and years of schooling.

\section{Methods}

This is a secondary analysis of a prospective cohort study, conducted between May 2005 and March 2007, with 831 pregnant women recruited from public sector primary care clinics in three administrative districts in Western São Paulo, Brazil. The aim of the original study was to evaluate the prevalence of and factors associated with common mental disorders during pregnancy among low-income women. A detailed description of the original study sample has been described elsewhere. ${ }^{9}$ The present cross-sectional study restricted the analysis to adolescent pregnant women $(n=168)$. Pregnant women were considered eligible if they were aged 16-19 years, between 20 and 30 weeks of gestation, had a naturally occurring conception with a singleton pregnancy, and received antenatal care in primary care clinics in the study area. Pregnant women with a history of psychosis were excluded. Eligible women who agreed to participate were asked to sign a consent form prior to engaging in a private face-to-face interview.

A questionnaire was used to elicit information about the main outcome (pregnancy planning) and covariates. Planning of current pregnancy was evaluated through a direct question ("was this pregnancy planned?"). All the participants answered this question during the interviews at primary care clinics. They were oriented to classify the pregnancy as either "planned" or "not planned," based on the following definitions. Planned pregnancy referred to a woman who was attempting pregnancy at the time of conception.
Unplanned pregnancy referred to women who were not attempting to get pregnant at the time of conception, even if she intended to become pregnant in the future.

Sociodemographic and economic characteristics of the participants were: age (16/17 and 18/19 years), years of schooling (0-8 and $>8$ [ie, high school]), partner status (living with someone/married or single), skin color (white and other), "wealth or asset score" (in tertiles), monthly family income (0-232 USD and 233-1.600 USD), and crowding (defined as number of adults and children living in the house divided by the number of rooms in the house: $0.1-0.9,0.91-1.4$, and 1.5-8.5).

The study area comprised a heterogeneous population of $\sim 400,000$ inhabitants, where people with high, medium, and low income live near one another. Brazil has systems of both public and private health care, though private health care is usually only accessible for women from the middle and upper middle classes. The public primary care clinics offer free antenatal care for all women, including adolescents, who live in their catchment areas. Antenatal care for either adolescent or adult women is offered regularly, typically once a month, and generally starting as soon as the woman seeks a pregnancy test at one of these clinics. Women followed in these primary care clinics are at low obstetrical risk; high-risk pregnancies are referred to regional hospitals for prenatal care. There were two public hospitals in the study area, providing 2,000 deliveries per year. All the interviews were performed by a trained research assistant at the public primary care clinics. The original study was approved by the ethics committees of the University Hospital and of the Health Secretariat of the city of São Paulo.

The prevalence of planned pregnancy was estimated with its $95 \%$ confidence interval $(95 \% \mathrm{CI})$. All the variables were analyzed as categorical variables. Statistical associations were examined with chi-square tests for independence. Logistic regression was used to estimate the association between years of schooling and planned pregnancy control for covariates. All the statistical analyses were performed using STATA version 11 (StataCorp LP, College Station, TX, USA).

\section{Results}

In total, $168(20.3 \%)$ adolescents among the 831 pregnant women in the main cohort were included in this study. The mean age of the sample was 17.7 years (range 16-19 years). Other sample characteristics included self-reported white skin color (49\%), having a partner or being married $(62 \%)$, and having a family monthly income $<232$ USD 
Table I Baseline sociodemographic of pregnant adolescent participants

\begin{tabular}{|c|c|c|c|c|}
\hline Variables & $\begin{array}{l}\text { Total } \\
(n=168)\end{array}$ & $\begin{array}{l}\text { Unplanned } \\
\text { pregnancy } \\
(n=I 29)\end{array}$ & $\begin{array}{l}\text { Planned } \\
\text { pregnancy } \\
(n=39)\end{array}$ & $\begin{array}{l}\text { Chi-square } \\
\text { test }\end{array}$ \\
\hline \multicolumn{5}{|l|}{ Age (years) } \\
\hline $16-17$ & 70 (42\%) & $57(44 \%)$ & $13(33 \%)$ & $P=0.23$ \\
\hline $8-19$ & $98(58 \%)$ & $72(56 \%)$ & $26(67 \%)$ & \\
\hline \multicolumn{5}{|l|}{ Color } \\
\hline White & $83(49 \%)$ & $60(47 \%)$ & $23(59 \%)$ & $P=0.17$ \\
\hline Other & $85(51 \%)$ & $69(53 \%)$ & $16(41 \%)$ & \\
\hline \multicolumn{5}{|l|}{ Partner status } \\
\hline Single & $63(38 \%)$ & $60(47 \%)$ & $3(8 \%)$ & $P<0.001$ \\
\hline Has partner & $105(62 \%)$ & $69(53 \%)$ & $36(92 \%)$ & \\
\hline \multicolumn{5}{|c|}{ Education (years) } \\
\hline $0-8$ & 81 (48\%) & $56(43 \%)$ & $25(64 \%)$ & $P=0.023$ \\
\hline$\geq 9$ & $87(52 \%)$ & $73(57 \%)$ & $14(36 \%)$ & \\
\hline \multicolumn{5}{|c|}{ Monthly income (USD) } \\
\hline $0-232$ & $83(49 \%)$ & 61 (47\%) & $22(56 \%)$ & $P=0.32$ \\
\hline$\geq 233$ & $85(51 \%)$ & $68(53 \%)$ & $17(44 \%)$ & \\
\hline \multicolumn{5}{|l|}{ Wealth score } \\
\hline $0-5$ & $66(39 \%)$ & $5 \mathrm{I}(40 \%)$ & 15 (38\%) & $P=0.90$ \\
\hline 6-9 & 102 (6I\%) & $78(60 \%)$ & $24(62 \%)$ & \\
\hline \multicolumn{5}{|l|}{ Crowding } \\
\hline 0 & $33(20 \%)$ & 27 (2।\%) & $6(15 \%)$ & $P=0.68$ \\
\hline I & 49 (29\%) & $36(28 \%)$ & $13(34 \%)$ & \\
\hline 2 & $86(51 \%)$ & $66(51 \%)$ & 20 (5I\%) & \\
\hline
\end{tabular}

(49\%). Sixty-six participants (39\%) had an asset score between 0 and 5 and approximately half $(51 \%)$ were in the highest tertile of crowding. More than half of these women $(52 \%)$ had less than high school education $(<9$ years of education) (Table 1). The prevalence of planned pregnancy was $23 \%$. In the bivariate analysis, planned pregnancy was associated with lower years of education (OR: 1.92; 95\% CI: 1.07-3.43) and having a partner (OR: 7.2; 95\% CI: 2.30-22.5) (Table 2). Table 2 also reports the results from the fully adjusted multivariate regression analysis and includes all covariates. In the multivariate analysis, it was found that there is an association between lower years of education and planned pregnancy (OR: 1.82; 95\% CI: $1.02-3.23)$.

\section{Discussion}

The main results of this study showed that in the Brazilian Public Health System, approximately one in four female adolescents planned their pregnancies and there is an association between planning of pregnancy and lower years of education. The prevalence of planned pregnancy among adolescents is consistent with the studies in Brazil and other low-to middle-income countries. In one study of 2,557 pregnant women from Rio Grande do Sul State (Southern Brazil), the
Table 2 Association between years of education and planned pregnancy using Poisson regression

\begin{tabular}{|c|c|c|c|c|}
\hline \multirow[t]{2}{*}{ Variables } & \multicolumn{2}{|c|}{ Unadjusted } & \multicolumn{2}{|c|}{ Adjusted } \\
\hline & OR & $95 \% \mathrm{Cl}$ & OR & $95 \% \mathrm{Cl}$ \\
\hline \multicolumn{5}{|l|}{ Age (years) } \\
\hline $16-17$ & 1 & & I & \\
\hline $18-19$ & 1.43 & $0.79-2.58$ & 1.28 & $0.72-2.29$ \\
\hline \multicolumn{5}{|l|}{ Color } \\
\hline White & I & & 1 & \\
\hline Other & 0.68 & $0.39-1.19$ & 0.58 & $0.34-0.97$ \\
\hline \multicolumn{5}{|c|}{ Partner status } \\
\hline Single & 1 & & 1 & \\
\hline Married & 7.20 & $2.30-22.5$ & 6.95 & $2.33-20.69$ \\
\hline \multicolumn{5}{|c|}{ Education (years) } \\
\hline$\geq 9$ & 1 & & I & \\
\hline $0-8$ & 1.92 & $1.07-3.43$ & 1.82 & $1.02-3.23$ \\
\hline \multicolumn{5}{|c|}{ Income (USD) } \\
\hline $0-232$ & 1 & & I & \\
\hline$\geq 233$ & 0.75 & $0.43-1.32$ & 0.88 & $0.50-1.56$ \\
\hline \multicolumn{5}{|c|}{ Wealth score } \\
\hline $0-5$ & I & & I & \\
\hline 6-9 & 1.04 & $0.59-1.83$ & 1.37 & $0.8 \mathrm{I}-2.30$ \\
\hline \multicolumn{5}{|l|}{ Crowding } \\
\hline 0 & 1 & & I & \\
\hline 1 & 1.46 & $0.62-3.46$ & 1.24 & $0.54-2.83$ \\
\hline 2 & 1.28 & $0.56-2.91$ & 1.31 & $0.6 I-2.82$ \\
\hline
\end{tabular}

Notes: $\mathrm{N}=168$; planned pregnancy $\mathrm{n}=39$.

Abbreviations: $\mathrm{OR}$, odds ratio; $\mathrm{Cl}$, confidence interval.

prevalence of planned pregnancy among women younger than 20 years of age was $27.3 \% .^{7}$ Another Brazilian study with 1,000 low-income pregnant teenagers admitted to a Brazilian public maternity hospital in São Paulo from 2001 to 2002 found that $18.8 \%$ had planned their pregnancies. ${ }^{10}$ The estimates for planned pregnancies in low- to middleincome countries are generally low, varying between $9.1 \%$ and $36 \%{ }^{11}$ In the Central Region of Ghana, a study found the prevalence of planned pregnancy to be $9.1 \%$ among 1,914 pregnant women attending antenatal clinics in four health facilities in the Mfantseman Municipality, including 340 women aged $<20$ years. ${ }^{12}$

Studies about motherhood during adolescence have mostly focused on unintended or unplanned pregnancy. Few of these studies have suggested that pregnancy in adolescence is related to social risk situations such as a decrease in schooling. The number of years in schooling is important because education is a proxy for socioeconomic status over the life course and pregnancy can interrupt schooling. Often pregnancy is not desired; therefore, it is not planned and it is considered to be the result of lack of information ${ }^{13,14}$ and of an unfavorable socioeconomic situation. ${ }^{15}$ One possible explanation for the association between low education (and low family income) with adolescent motherhood is that women 
with less schooling and unfavorable socioeconomic conditions may have less access to information and health services and, consequently, to contraceptive methods. However, it is also possible that in this social group, there is greater desire to have children in adolescence. Possible reasons for this would be personal or family goals, including desire to get married, achievement of higher status, search for autonomy, or even affirmation of reproductive capacity. ${ }^{16}$

Qualitative studies have attempted to address the social and cultural meanings of pregnancy during adolescence. One study focused on a group of low-income youth in Belém, Pará State, Brazil, described adolescent pregnancy and motherhood from a socio-anthropological perspective and found that for adolescent girls, pregnancy does not mean a break with life goals. In fact, pregnancy and motherhood are valued to the extent that they produce changes in social status for the adolescent, in terms of affirmation of goals for social mobility in the future. ${ }^{17}$ Some studies have shown that pregnancy was desired by adolescent girls ${ }^{18}$ and that pregnancy was not a negative experience for most of them. ${ }^{15,19}$ In certain situations, early pregnancy can be the solution to conflict situations and not necessarily a problem in itself. ${ }^{20,21}$

There are several investigations regarding the relationship between motherhood during adolescence and level of education. ${ }^{22-26}$ In Brazil, a girl's education level has been considered the most important factor associated with adolescent pregnancy. ${ }^{26}$ Almeida and Aquino ${ }^{27}$ analyzed data from a population-based survey conducted in three Brazilian cities of a representative sample of girls and boys between the ages of 18 and 24 years who have different social and cultural backgrounds aiming to study the association between adolescent pregnancy and completion of basic education. They found that for both boys and girls, coming from a household with low per capita family income and having a mother with a low level of education were the factors strongly associated with noncompletion of basic education. They concluded that adolescent pregnancy was also a factor associated with noncompletion of school, adding to the preexisting disadvantages related to the adolescent's social and cultural background. ${ }^{27}$ Gupta and Leite ${ }^{26}$ analyzed the results of demographic surveys in Northeast Brazil in 1986, 1991, and 1996 and concluded that 15- to 19-year-old girls with low educational levels consistently showed at least twice the probability of having a child compared to those with more schooling. Education was also highly associated with postponing the birth of the first child among adolescent girls in the Northeast.
During the 3 years of study (1986, 1981, and 1996), even controlling for age and other economic and cultural characteristics, the impact of educational level remained as an important factor: adolescents with $\leq 4$ years of schooling had at least twice the probability of having a child before the age of 20 years, compared to those with at least 5 years of schooling. ${ }^{26}$ In contrast with the results of previous research, the present study found that lower education was independently associated with planning the pregnancy. The apparent contradiction can be explained by the homogeneity of the sample. All pregnant adolescents included in this study were socially disadvantaged. So among these poor pregnant women, a possible explanation for the association between low education and planning of pregnancy is that pregnancy becomes an option for young people who have difficulties with educational attainment. Alternatively, one might think that by opting for pregnancy, the adolescent disrupts school activities. It is known that middle- and upper-class teenagers generally receive financial and material support, thereby reducing the impact of teenage parenthood on the person's educational development. ${ }^{28}$ Furthermore, abortion, an illegal procedure in Brazil, is more common among middle- and upper-class teenagers. Less-privileged teenagers cannot afford the high cost of abortion and then are obliged to carry the pregnancy to term which negatively affects their education. ${ }^{29}$

One of the strengths of this study is the size of the sample, consisting of 168 low- or low- to middle-income pregnant women. Moreover, the adolescents in this sample used public health services, which is representative of the type of medical care received by $\sim 50 \%$ of the general Brazilian population.

The present study has some limitations. First, recall or reporting bias may occur (ie, social desirability bias). Hence, pregnant teenage women would feel more comfortable saying that a pregnancy was planned, especially if married. If this were the case, there would be an even lower prevalence of planned pregnancy. By contrast, it could also be expected that some teens, more likely those without partners, would have said that their pregnancy was not planned when perhaps it was. Second, planning of the pregnancy was evaluated through a single question. Nowadays, pregnancy intention can be assessed with psychometrically valid measurements, and it is possible to classify women with "unplanned pregnancy" as women with "mistimed pregnancy." It is also assumed that dichotomization of pregnancies into planned and unplanned does not allow one to express ambivalence. ${ }^{30}$ Third, in a cross-sectional study, inferences cannot be drawn about causation. Therefore, this sample is limited to 
estimates from a single time period. Fourth, there may be other unmeasured socioeconomic variables confounding the association between planned pregnancy and lower years of education. However, the three socioeconomic variables included in the multivariate analysis (crowding, asset score, and family monthly income) evaluate different aspects of socioeconomic status.

\section{Conclusion}

In the study of low-income Brazilian adolescent females, pregnancy planning was independently associated with lower years of education. Future studies are needed to determine the specific mechanisms for adolescents who may choose to plan pregnancy rather than pursue educational attainment.

\section{Acknowledgments}

The authors would like to thank the research team responsible for collecting the data. This research was funded by Fulbright-Brazil Scientific Mobility Program and T32 MH20021-14 (Hsiang Huang), FAPESP (05/05333-9; FaisalCury), and Lemann Institute for Brazilian Studies Faculty Research Grant (Karen M. Tabb).

\section{Disclosure}

The authors report no conflicts of interest in this work.

\section{References}

1. Tyrberg RB, Blomberg M, Kjølhede P. Deliveries among teenage women-with emphasis on incidence and mode of delivery: a Swedish national survey from 1973 to 2010. BMC Pregnancy Childbirth. 2013; 13(1):204.

2. Cunnington AJ. What's so bad about teenage pregnancy? J Fam Plann Reprod Health Care. 2001;27(1):36-41.

3. Ganchimeg T, Mori R, Ota E, et al. Maternal and perinatal outcomes among nulliparous adolescents in low- and middle-income countries: a multi-country study. BJOG. 2013;120(13):1622-1630; discussion 1630.

4. Olausson PO, Haglund B, Weitoft GR, Cnattingius S. Teenage childbearing and long-term socioeconomic consequences: a case study in Sweden. Fam Plann Perspect. 2001;33(2):70-74.

5. Wellings $\mathrm{K}$, Jones KG, Mercer $\mathrm{CH}$, et al. The prevalence of unplanned pregnancy and associated factors in Britain: findings from the third National Survey of Sexual Attitudes and Lifestyles (Natsal-3). Lancet. 2013;382(9907):1807-1816.

6. Kane JB, Morgan SP, Harris KM, Guilkey DK. The educational consequences of teen childbearing. Demography. 2013;50(6):2129-2150.

7. Prietsch SO, González-Chica DA, Cesar JA, Mendoza-Sassi RA. [Unplanned pregnancy in Southern Brazil: prevalence and associated factors]. Cad Saude Publica. 2011;27(10):1906-1916. Portuguese.

8. Heilborn ML, Cabral CS. A new look at teenage pregnancy in Brazil. ISRN Obstet Gynecol. 2011;2011:975234.

9. Faisal-Cury A, Menezes P, Araya R, Zugaib M. Common mental disorders during pregnancy: prevalence and associated factors among low-income women in Sao Paulo, Brazil. Arch Women Ment Hlth. 2009;12(5):335-343.
10. Chalem E, Mitsuhiro SS, Ferri CP, Barros MC, Guinsburg R, Laranjeira R. [Teenage pregnancy: behavioral and socio-demographic profile of an urban Brazilian population]. Cad Saude Publica. 2007;23(1):177-186. Portuguese.

11. Ali S, Mohammed S, Mungrue K. The epidemiology of unplanned pregnancies in North-Central Trinidad. Int J Adolesc Med Health. 2009;21(1): 73-78.

12. Eliason S, Baiden F, Yankey BA, Awusabo-Asare K. Determinants of unintended pregnancies in rural Ghana. BMC Pregnancy Childbirth. 2014;14:261.

13. Bennett T, Skatrud JD, Guild P, Loda F, Klerman LV. Rural adolescent pregnancy: a view from the South. Fam Plann Perspect. 1997;29(6): 256-260,267.

14. Langeni TT. Intergenerational transmission of reproductive behaviour in Botswana. J Biosoc Sci. 2011;43(1):51-63.

15. dos Santos SR, Schor N. Vivências da maternidade na adolescência precoce. [Experiencing motherhood in early adolescence]. Rev Saude Publica. 2003;37(1):15-23. Portuguese.

16. Gigante DP, Barros FC, Veleda R, Gonçalves H, Horta BL, Victora CG. Maternity and paternity in the Pelotas birth cohort from 1982 to 2004 2005, Southern Brazil. Rev Saude Publica. 2008;42(Suppl 2):42-50.

17. Pantoja AL. "Ser alguém na vida": uma análise sócio-antropológica da gravidez/maternidade na adolescência, em Belém do Pará, Brasil. ["Be someone in life": a socio-anthropological analysis of adolescent pregnancy and motherhood in Belém, Pará State, Brazil]. Cad Saude Publica. 2003;19(Suppl 2):S335-S343. Portuguese.

18. Rajapaksa-Hewageegana N, Salway S, Piercy H, Samarage S. A quantitative exploration of the sociocultural context of teenage pregnancy in Sri Lanka. BMC Pregnancy Childbirth. 2014;14(1):394.

19. Shaw M, Lawlor DA, Najman JM. Teenage children of teenage mothers: psychological, behavioural and health outcomes from an Australian prospective longitudinal study. Soc Sci Med. 2006;62(10):2526-2539.

20. Ferraro AA, Cardoso VC, Barbosa AP, et al. Childbearing in adolescence: intergenerational dejà-vu? Evidence from a Brazilian birth cohort. BMC Pregnancy Childbirth. 2013;13:149.

21. Bonell C, Allen E, Strange V, et al. Influence of family type and parenting behaviours on teenage sexual behaviour and conceptions. J Epidemiol Community Health. 2006;60(6):502-506.

22. Singh S. Adolescent childbearing in developing countries: a global review. Stud Fam Plann. 1998;29(2):117-136.

23. Sabroza AR, Leal MoC, Souza PR, Gama SG. [Some emotional repercussions of adolescent pregnancy in Rio de Janeiro, Brazil (1999-2001)] Cad Saude Publica. 2004;20(Suppl 1):S130-S137. Portuguese.

24. Zeck W, Bjelic-Radisic V, Haas J, Greimel E. Impact of adolescent pregnancy on the future life of young mothers in terms of social, familial, and educational changes. $J$ Adolesc Health. 2007;41(4):380-388.

25. Almeida MaC, Aquino EM, de Barros AP. School trajectory and teenage pregnancy in three Brazilian state capitals. Cad Saude Publica. 2006; 22(7):1397-1409.

26. Gupta N, da Costa Leite I. Adolescent fertility behavior: trends and determinants in northeastern Brazil. Int Fam Plann Perspect. 1999; 25(3):125-130.

27. Almeida MaC, Aquino EM. Adolescent pregnancy and completion of basic education: a study of young people in three state capital cities in Brazil. Cad Saude Publica. 2011;27(12):2386-2400.

28. Brandão ER, Heilborn ML. Sexualidade e gravidez na adolescência entre jovens de camadas médias do Rio de Janeiro, Brasil Middle-class teenage sexuality and pregnancy in Rio de Janeiro, Brazil. Cad Saúde Pública. 2006;22(7):1421-1430.

29. Menezes GM, Aquino EM, da Silva DO. Induced abortion during youth: social inequalities in the outcome of the first pregnancy. Cad Saude Publica. 2006;22(7):1431-1446.

30. Barrett G, Smith S, Wellings K. Conceptualisation, development and evaluation of a measure of unplanned pregnancy. $J$ Epidemiol Community Health. 2004;58:426-433. 
International Journal of Women's Health

Dovepress

\section{Publish your work in this journal}

The International Journal of Women's Health is an international, peerreviewed open-access journal publishing original research, reports, editorials, reviews and commentaries on all aspects of women's healthcare including gynecology, obstetrics, and breast cancer. The manuscript management system is completely online and includes Visit http://www.dovepress.com/testimonials.php to read real quotes from published authors.

Submit your manuscript here: http://www.dovepress.com/international-journal-of-womens-health-journal 